\title{
COBALT ELECTRODEPOSITION ONTO HIGHLY ORIENTED PYROLYTIC GRAPHITE (HOPG) ELECTRODE FROM AMMONIUM SULFATE SOLUTIONS
}

\author{
Luis Humberto Mendoza-Huizar* y Clara Hilda Rios-Reyes \\ Centro de Investigaciones Químicas, Mineral de la Reforma, Universidad Autónoma del Estado de Hidalgo, CP 42186, Hidalgo, México \\ Margarita Rivera \\ Departamento Materia Condensada, Instituto de Física, Universidad Nacional Autónoma de México, Ciudad Universitaria, \\ CP 04510, México D.F., México
}

Recebido em 1/9/09; aceito em 22/1/10; publicado na web em 3/5/10

\begin{abstract}
It was carried out an electrochemical study of the cobalt electrodeposition onto $\mathrm{HOPG}$ electrode from an aqueous solution containing $10^{-2} \mathrm{M}$ of $\mathrm{CoSO}_{4}+1 \mathrm{M}\left(\mathrm{NH}_{4}\right)_{2} \mathrm{SO}_{4}$. Nucleation parameters such as nucleation rate, density of active nucleation sites, saturation nucleus and the rate constant of the proton reduction reaction $\left(k_{\mathrm{PR}}\right)$ were determined from potentiostatic studies. An increase in $k_{\mathrm{PR}}$ values with the decrease in the applied potential suggested a competition between $\mathrm{H}^{+}$and $\mathrm{Co}^{2+}$ by the active sites on the surface. The $\Delta G$ energy calculated for the formation of stable nucleus was $8.21 \times 10^{-21} \mathrm{~J} /$ nuclei. The AFM study indicated the formation of small clusters of $50-400 \mathrm{~nm}$ in diameter and 2-120 $\mathrm{nm}$ in height.
\end{abstract}

Keyword: cobalt; HOPG; sulfate.

\section{INTRODUCTION}

Cobalt electrodeposits have attracted a great interest in view of their potential applications in digital information storage. Most of the Co electrodeposition studies have been performed onto carbon electrodes $^{1-17}$ and some others onto stainless steel, ${ }^{18,19}$ gold, ${ }^{20-22}$ nickel, ${ }^{23}$ copper $^{24}$ and platinum ${ }^{25}$ electrodes. Probably, carbon electrodes are the preferred substrates because they offer an inert surface in where it is possible to study the nucleation and growth process neglecting the metal-metal interaction. However, Co electrodeposition onto highly oriented pyrolytic graphite (HOPG) surfaces has been scarcely investigated. ${ }^{12-15}$ Recently, it has been analyzed the initial stages of the Co electrodeposition process onto HOPG electrodes from sodium and ammonium sulfate solutions employing atomic force microscopy. ${ }^{15}$ In such work, it was investigated the cationic influence on the nucleation process of Co nano-size aggregates. From the electrochemical results, it was observed that the kind of ion in solution influences the cluster formation energy as well as the growth rate as a function of the reduction potential. However, a kinetic analysis of the nucleation parameters from ammonium sulfate solutions on HOPG electrodes is missing yet. Thus, in this work, it was carried out an electrochemical study, to determine these parameters, in order to understand the Co electrodeposition process from this system.

\section{EXPERIMENTAL}

Co electrodeposits onto HOPG were carried out from an aqueous solutions containing $10^{-2} \mathrm{M}$ of $\mathrm{CoSO}_{4}+1 \mathrm{M}\left(\mathrm{NH}_{4}\right)_{2} \mathrm{SO}_{4}$ at $\mathrm{pH} 4.5$ (natural $\mathrm{pH}$ ). All solutions were prepared by using analytic grade reagents with ultra pure water (Millipore-Q system) and were deoxygenated by bubbling $\mathrm{N}_{2}$ for $15 \mathrm{~min}$ before each experiment. Once the solution was deoxygenated a nitrogen atmosphere was maintained over the solutions. During the experiment the bubbling was stopped to avoid the presence of additional diffusional variables caused by the nitrogen bubbles on the electrode surface. The working electrodes were freshly cleaved HOPG surfaces. A graphite bar with an exposed

*e-mail: hhuizar@uaeh.edu.mx area greater than the working electrode was used as counter electrode. A saturated silver electrode $(\mathrm{Ag} / \mathrm{AgCl})$ was used as the reference electrode, and all measured potentials are referred to this scale. The electrochemical experiments were carried out in a BAS potentiostat connected to a personal computer running the BAS100W software to allow the control of experiments and data acquisition. In order to verify the electrochemical behavior of the electrode in the electrodeposition bath, cyclic voltammetry was performed in the 0.600 to $-1.300 \mathrm{~V}$ potential range. The kinetic mechanism of Co deposit onto HOPG was studied under potentiostatic conditions by the analysis of the experimental potentiostatic current density transients obtained with the potential step technique. In all cases, the perturbation of the potential electrode always started at $0.600 \mathrm{~V}$ because this is the null current zone in where the Co deposition had not still begun. Thus, the application of this potential guarantees that the electrochemical signals recorded during the cathodic polarization are caused by the cobalt electroreduction on the electrode. ${ }^{20}$ The potential step was imposed at different potentials detailed in this work. Microstructures of electrodeposits were examined by using atomic force microscopy (AFM), the images were obtained with a Jeol JSPM 4210 microscope.

\section{RESULTS AND DISCUSSION}

\section{Cyclic voltammetry}

In previous work it was found that, under the experimental conditions used in this work, the predominant chemical species is a cobalt sulfate pentaquo complex $\left[\mathrm{Co}\left(\mathrm{SO}_{4}\right)\left(\mathrm{H}_{2} \mathrm{O}\right)_{5}\right]$ where the equilibrium potential for the $\left[\mathrm{Co}\left(\mathrm{SO}_{4}\right)\left(\mathrm{H}_{2} \mathrm{O}\right)_{5}\right] / \mathrm{Co}^{0}$ couple is -0.353 $\mathrm{V}$ vs $\mathrm{NHE}(-0.552 \mathrm{~V}$ vs $\mathrm{Ag} / \mathrm{AgCl}$ (satd. $\mathrm{KCl})) .{ }^{17}$ It was suggested that the existence of free electrons through sulfate group allows a faster adsorption process on the electrode surface. ${ }^{17}$ Figure 1 shows the voltammetric response, at the scan rate of $20 \mathrm{mVs}^{-1}$, obtained from $\mathrm{HOPG} / 10^{-2} \mathrm{M}$ of $\mathrm{CoSO}_{4}+1 \mathrm{M}\left(\mathrm{NH}_{4}\right)_{2} \mathrm{SO}_{4}$ system. At direct scan it can be observed that the Co electrodeposition starts at -0.700 $\mathrm{V}\left(E_{\mathrm{c}}\right)$ approximately. It was not possible to detect the formation of a cathodic peak due probably to the overlapping of $\mathrm{Co}$ and proton reduction processes. Here, it must be considered that the cathodic 
peak current is originated by two components, the first one is the transitory current needed to adjust the concentration of the reactive on the surface to the equilibrium concentration and the second one is the current controlled by diffusion. ${ }^{26}$ Typically, the first current decreases fast when the diffusion layer is extended on the surface. However, if another reduction process occurs when the first current starts to diminish then both currents are overlapping and the maximum in the voltammogram may be not observed. Moreover, it has been reported that the formation of cobalt nucleus favors the proton reduction process. ${ }^{4}$ Thus, when the cobalt nucleus is formed on the surface, onto this occurs a proton reduction process increasing the current recorded in the voltammogram. An alternative to determine the presence of cathodic peaks is choosing different substrates in where the electron charge transfer constant is different. However, the detection of cathodic peaks onto different substrates is beyond of the scope of this paper because the determination of kinetic parameters is done through potentiostatic studies. During the inverse potential scan, it was recorded the crossover $E_{\mathrm{e}}$ at $-0.640 \mathrm{~V}$. In the anodic zone were detected two principal peaks $\mathrm{A}$ and $\mathrm{B}$ at around -0.486 and $-0.276 \mathrm{~V}$, respectively. Peaks A and B have been related to the dissolution of different Co phases deposited during the direct scan. On the other hand, peak A has been associated to the dissolution of a hydrogen rich Co phase. ${ }^{4}$

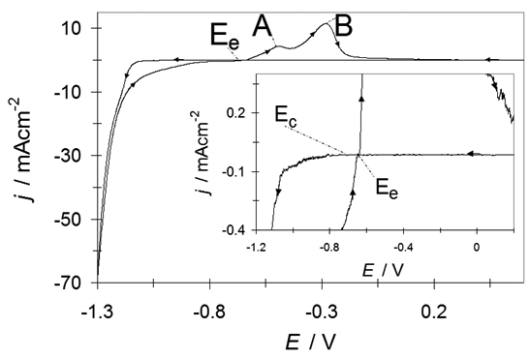

Figure 1. A typical cyclic voltammogram obtained from the $\mathrm{HOPG} / 10^{-2} \mathrm{M}$ of $\mathrm{CoSO}_{4}+1 \mathrm{M} \mathrm{NH}_{4} \mathrm{SO}_{4}(\mathrm{pH} 4.5)$ system. The potential scan rate was started at $0.600 \mathrm{~V}$ toward the negative direction with a potential scan rate of $20 \mathrm{mV} \mathrm{s}^{-1}$

\section{Chronoamperometric study}

Formation of new phases generally occurs through nucleation and growth mechanisms and the corresponding current transients can provide valuable information about the kinetics of electrodeposition process. Figure 2 shows a set of current density transients (current density $(j)$ vs time $(t)$ ) recorded at different potentials by a step potential technique. These transients were obtained by applying an initial potential of $0.600 \mathrm{~V}$ on the surface of the HOPG electrode. At this potential value, the Co deposition had not still begun. After the application of this initial potential, a step of negative potential was varied on the surface of the electrode. Once the current maximum $\left(j_{\mathrm{m}}\right)$ has been reached at a characteristic time $\left(t_{\mathrm{m}}\right)$, a decay of the current was obtained. Apparently, the general shape of these transients is very similar to those reported for a three dimensional nucleation process with diffusion control (3D-dc). ${ }^{27,28}$ A classification of the nucleation as instantaneous or progressive is possible by following the criteria established by Sharifker et al. in where the experimental transients in a non-dimensional form by plotting $j^{2} / j_{\mathrm{m}}{ }^{2} \mathrm{vs} t / t_{\mathrm{m}}$ are compared with those theoretically generated from Equations 1 and 2 for instantaneous and progressive nucleation, respectively. ${ }^{27}$

$$
\frac{j^{2}}{j_{m}^{2}}=1.9254\left(\frac{t}{t_{m}}\right)^{-1}\left\{1-\exp \left[-1.2564\left(\frac{t}{t_{m}}\right)\right]\right\}^{2}
$$

$$
\frac{j^{2}}{j_{m}^{2}}=1.2254\left(\frac{t}{t_{m}}\right)^{-1}\left\{1-\exp \left[-2.3367\left(\frac{t}{t_{m}}\right)^{2}\right]\right\}^{2}
$$

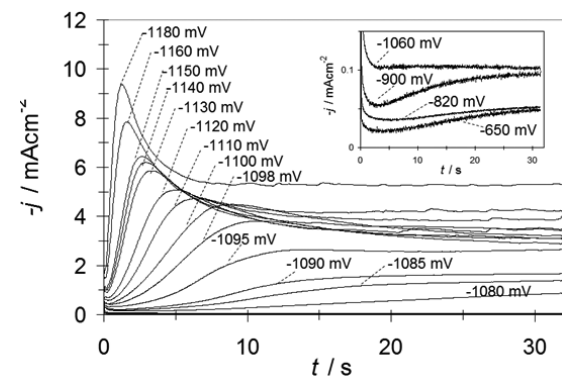

Figure 2. A set of transients obtained from $\mathrm{HOPG} / 10^{-2} \mathrm{M}$ of $\mathrm{CoSO}_{4}+1 \mathrm{M}$ $\mathrm{NH}_{4} \mathrm{SO}_{4}(\mathrm{pH} 4.5)$ system by means of the potential step technique for different potential step values $(\mathrm{mV})$ indicated in the figure. In all the cases, the initial potential was $0.600 \mathrm{~V}$

Figure 3 shows a comparison of different experimental current transients normalized through the coordinates of its respective local maximum $\left(t_{\mathrm{m}}, j_{\mathrm{m}}\right)$, with the theoretical non-dimensional curves corresponding to a $3 \mathrm{D}$ instantaneous and progressive nucleation. Although, these kinds of plots have been strongly criticized by Hermann and Tarallo suggesting that such representations must be discouraged; because their utility to get qualitative conclusions is not definitive in all cases. ${ }^{29}$ From these plots, it is clear that most of the experimental data fall within the range of validity of the theory proposed by Scharifker et al.. ${ }^{27,28}$ On the other hand, note that at $t / t_{\mathrm{m}}<1$ the experimental curve follows the response predicted for a $3 \mathrm{D}$ progressive nucleation meanwhile for $t / t_{\mathrm{m}}>1$ it follows the response predicted for a 3D instantaneous nucleation. As a transition from instantaneous to progressive nucleation would seem impossible, this may be indicative of the presence of other contributions to the overall current during the early stages of the cobalt deposition process $\left(t / t_{\mathrm{m}}>1\right)$ apart from the $3 \mathrm{D}$ nucleation contribution. ${ }^{17,21}$ Rios-Reyes et al. have suggested that for the cobalt electrodeposition case the additional contribution is due to the proton reduction process. ${ }^{17}$

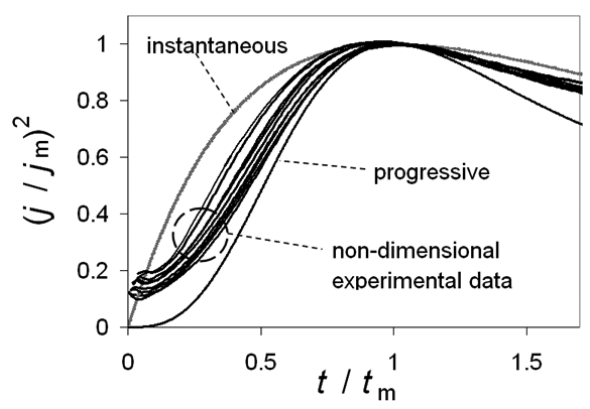

Figure 3. Comparison of different experimental and theoretical non-dimensional curves corresponding to a $3 D$ instantaneous nucleation (Equation 1) and $3 D$ progressive nucleation (Equation 2)

\section{Analysis of the transients from $\mathrm{CoSO}_{4}+\left(\mathrm{NH}_{4}\right)_{2} \mathrm{SO}_{4}$ system}

Peak A, in Figure 1, indicates the proton reduction process is present due to the existence of a hydrogen rich Co phase. ${ }^{4}$ It has been proposed that when the proton reduction occurs simultaneously with the diffusion-limited 3D growth of Co centers, the overall current density is given by: ${ }^{30}$ 
$j(t)=\left\{P_{1}^{*}+P_{4} t^{-1 / 2}\right\} \times\left\{1-\exp \left[-P_{2}\left(t-\frac{1-\exp \left(-P_{3} t\right)}{P_{3}}\right)\right]\right\}$

Where

$$
\begin{gathered}
P_{1}^{*}=P_{1}\left(\frac{2 c M}{\pi \rho}\right)^{1 / 2} \\
P_{1}=z_{P R} F k_{P R} \\
P_{2}=N_{0} \pi k D \\
P_{3}=A \\
P_{4}=\frac{2 F D^{1 / 2} c}{\pi^{1 / 2}} \\
k=\left(\frac{8 \pi c}{\rho}\right)^{1 / 2}
\end{gathered}
$$

where $z_{P R} F$ is the molar charge transferred during the proton reduction process, $k_{P R}$ is the rate constant of the proton reduction reaction, $N_{0}$ is the number of active nucleation sites, $A$ is the nucleation rate, $D$ is the diffusion coefficient, $F$ is the Faraday's constant and all others parameters have their conventional meanings. The parameters $\mathrm{P}_{1} *, \mathrm{P}_{1}, \mathrm{P}_{2}, \mathrm{P}_{3}$ and $\mathrm{P}_{4}$ showed in Equations 4-9 were defined to write a simple mathematical expression only for sake of simplicity. Figure 4 shows a comparison between an experimental current density transient recorded during Co electrodeposition onto a HOPG electrode when a potential value of $-1.100 \mathrm{~V}$ was applied with the theoretical transient generated by non-linear fitting of Equation 3 to the experimental data.

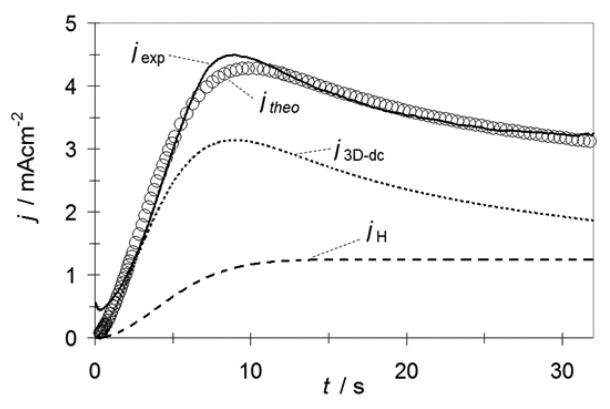

Figure 4. Comparison between an experimental current density transient (__ recorded at $-1.100 \mathrm{~V}$ with the theoretical transient (OOO) generated by non-linear fitting of Equation 3. $P_{1}^{*}=1.247 \mathrm{mAcm}^{-2}, P_{2}=1.219 \mathrm{~s}^{-1}$, $P_{3}=0.053 \mathrm{~s}^{-1}, P_{4}=10.549 \mathrm{mAcm}^{-2} \mathrm{~s}^{1 / 2}$. In this figure the different individual contributions are depicted

It can be observed the model expressed by this equation adequately accounted for the behavior of experimental transient. It is important to mention that similar fittings were obtained for the others experimental transients. The physical parameters obtained from the adjustments of Equation 3 are summarized on Table 1. The average diffusion coefficient calculated from the fittings was $2.5 \times 10^{-6} \mathrm{~cm}^{2}$ $\mathrm{s}^{-1}$. It is seen that an increment of the $k_{\mathrm{PR}}, A$ and $N_{0}$ is obtained when the overpotential applied is increased. It is interesting to observe that an increase in $k_{\mathrm{PR}}$ values indicates the reduction proton process is favored, suggesting a competition by the active sites on the surface by $\mathrm{H}^{+}$ions with the Co cations.
Table 1. Potential dependence for the nucleation parameters during Co electrodeposition onto a $\mathrm{HOPG}$ electrode from an aqueous solution containing $10^{-2} \mathrm{M}$ of $\mathrm{CoSO}_{4}+1 \mathrm{M}\left(\mathrm{NH}_{4}\right)_{2} \mathrm{SO}_{4}$. The values were obtained from best-fit parameters found through the fitting process of the experimental $j$ - $t$ plots using Equation 3

\begin{tabular}{lccc}
\hline$E / \mathrm{mV}$ & $k_{\mathrm{PR}} \times 10^{6} / \mathrm{cm}^{2} \mathrm{~s}^{-1}$ & $A \times 10^{2} / \mathrm{cm}^{2} \mathrm{~s}^{-1}$ & $N_{0} \mathrm{X} 10^{-4} / \mathrm{cm}^{-2}$ \\
\hline-650 & 0.006 & 0.021 & 0.048 \\
-820 & 0.008 & 0.026 & 0.049 \\
-900 & 0.008 & 0.029 & 0.047 \\
-1060 & 10.201 & 1.912 & 0.088 \\
-1080 & 15.600 & 1.837 & 0.215 \\
-1085 & 10.102 & 1.765 & 0.343 \\
-1090 & 12.384 & 2.213 & 0.402 \\
-1095 & 9.556 & 2.982 & 0.395 \\
-1098 & 10.419 & 3.762 & 0.631 \\
-1100 & 12.918 & 5.26 & 0.693 \\
-1110 & 14.057 & 4.618 & 1.687 \\
-1120 & 15.572 & 6.19 & 2.209 \\
-1130 & 19.978 & 10.225 & 3.466 \\
-1140 & 22.018 & 11.465 & 3.936 \\
-1150 & 26.733 & 10.502 & 5.485 \\
-1160 & 29.629 & 17.405 & 10.379 \\
-1180 & 42.355 & 47.740 & 70.604 \\
\hline
\end{tabular}

\section{Analysis of the kinetic parameters}

From the nucleation rates values reported in this work (Table 1) it is possible to calculate the Gibbs free energy of nucleation as: ${ }^{31,32}$

$$
A=k_{1} \exp \left(-\frac{\Delta G}{K_{B} T}\right)=k_{1} \exp \left(\frac{k_{2}}{\eta^{2}}\right)
$$

where $\Delta G$ is the Gibbs free energy of nucleation, $\mathrm{J} /$ nuclei; $K_{B}$ is the Boltzmann constant $\left(1.3806610^{-23} \mathrm{~J} \mathrm{~mol}^{-1}\right), k_{1}=\mathrm{N}_{0} \omega_{n+c} \Gamma$ where, $\omega_{n+c}$ is the frequency of attachment of single atoms to the critical nucleus and $\Gamma$ is the non-equilibrium Zeldovich factor and depends exponentially on the overpotential. ${ }^{33}$ On the other hand, $\mathrm{k}_{2}=-\left(16 \pi \gamma^{3} M^{2} \phi(\theta) / 3 \rho^{2} z^{2} F^{2} k^{\prime} T\right)$, where $\gamma$ is the interfacial tension of nucleus with its motherphase, $\phi(\theta)$ is a function of the contact angle $\theta$ between the nucleus and the substrate and $k^{\prime}=\left(8 \pi C_{o} M / \rho\right)^{1 / 2}$ and all others parameters have their conventional meanings. ${ }^{33}$ In order to calculate the value of Gibbs free energy of nucleation from experimental transients, a $\ln A v s . \eta^{-2}$ plot can be constructed according to Equation 10, and then from the slope $k_{2}$ of the observed linear relationship, $\Delta G$ could be calculated at each particular overpotential by using Equation 11:

$$
\left(-\frac{\Delta G}{K_{B} T}\right)=\frac{k_{2}}{\eta^{2}}
$$

where $T$ is the absolute temperature, $K$. The plot $\ln A v s \eta^{-2}$ plot, showed a linear relationship, Figure 5; the $\Delta G$ calculated for this system was $8.21 \times 10^{-21} \mathrm{~J} /$ nuclei, since this energy corresponds to the $\Delta G$ value requirements for stable nucleus formation. ${ }^{31,32}$ The $\Delta G$ value obtained is lower than the values calculated for the electrocrystallization of $\mathrm{Ni}$ on carbon microelectrodes, ${ }^{34} \mathrm{Cu}$ on copper $^{35}$ and $\mathrm{Co}$ on carbon electrodes from sodium sulfate solutions. ${ }^{12}$

Through the physical constants reported (Table 1), it was also possible to calculate the saturation number of nuclei $\left(N_{s}\right)$. This estimation was made employing Equation 12:18

$$
N_{S}=\left(\frac{A N_{0}}{2 k D}\right)^{1 / 2}
$$




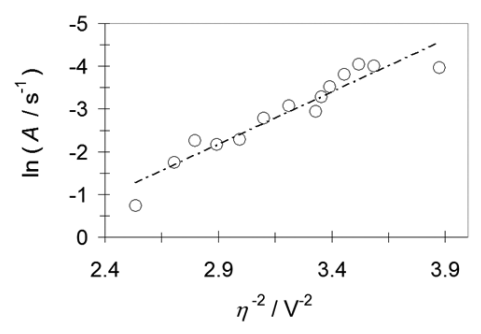

Figure 5. In A vs $\eta^{-2}$ plot used to calculate the Gibbs energy of nucleation according to Equation 11. The broken straight line corresponds to the linear fit of the experimental data

The results obtained for $N_{\mathrm{s}}$, are summarized on Table 2. Observe that the $N_{\mathrm{s}}$ values increased with the applied potential. It is important to mention that, because of the exclusion zones of the deposit, caused by the hemispherical diffusional gradients of 3D nucleus, $N_{\mathrm{s}}$ will be always lower than $N_{0}$ values at the same applied potential, and both grow in accordance with a more negative potential. The $N_{s} / N_{0}$ ratio which can be defined as the efficiency, of use of the surface available nucleation sites is reported (Table 2). Observe that the $N_{s} / N_{0}$ ratio is potential dependent and its value is relatively low. This result may be due to the occupation of active sites by $\left(\mathrm{NH}_{4}\right)^{+}$ions adsorbed on the surface. ${ }^{15}$

Table 2. Potential dependence of the $N_{\mathrm{s}}$ from an aqueous solution containing $10^{-2} \mathrm{M}$ of $\mathrm{CoSO}_{4}+1 \mathrm{M}\left(\mathrm{NH}_{4}\right)_{2} \mathrm{SO}_{4}$ calculated from physical constants reported in Table 1 and Equation 12

\begin{tabular}{ccc}
\hline$E / \mathrm{mV}$ & $N_{\mathrm{s}} \mathrm{X} 10^{-4} / \mathrm{cm}^{-2}$ & $N_{\mathrm{s}} / N_{0}$ \\
\hline-650 & 0.003 & 0.062 \\
-820 & 0.003 & 0.069 \\
-900 & 0.003 & 0.074 \\
-1060 & 0.039 & 0.441 \\
-1080 & 0.059 & 0.276 \\
-1085 & 0.074 & 0.214 \\
-1090 & 0.089 & 0.222 \\
-1095 & 0.102 & 0.260 \\
-1098 & 0.145 & 0.231 \\
-1100 & 0.180 & 0.260 \\
-1110 & 0.264 & 0.156 \\
-1120 & 0.349 & 0.158 \\
-1130 & 0.562 & 0.162 \\
-1140 & 0.635 & 0.161 \\
-1150 & 0.717 & 0.131 \\
-1160 & 1.269 & 0.122 \\
-1180 & 5.484 & 0.078
\end{tabular}

In the framework of the atomistic theory of electrolytic nucleation, it is possible to estimate the critical size of the Co nucleus $(n)$ from the potential dependence of $A$ through the following equation: ${ }^{36}$

$$
n_{c}=\left(\frac{k_{B} T}{z e_{0}}\right)\left(\frac{d \ln A}{d \eta}\right)-\alpha_{C o}
$$

where $\alpha_{C o}$ is the transfer coefficient for Co reduction. The plots $\ln A$ vs $\eta$ showed a linear tendency (Figure $1 \mathrm{~S}$, supplementary material). Thus, the critical cluster's size calculated employing Equation 13 and $\alpha_{C o}=0.5$ was $n_{c}=0$, this value means that each active site is a critical nucleus.

\section{Morphological analysis}

In order to analyze the formation of nucleus onto the HOPG sur- face, we perform a morphological analysis of the deposits obtained at $-650,-820$ and $-900 \mathrm{mV}$ employing AFM. Only these potentials were analyzed because in the deposits obtained at lower potentials (>-1000) the nuclei's overlapping is fast, and it was not possible to analyze the nuclei distribution from such images. Figure 6 , show the AFM images obtained at $-820 \mathrm{mV}$, it is possible to note the formation of disperse small clusters of 50-400 nm in diameter and 2-120 nm in height. Similar results were obtained at -650 and $-900 \mathrm{mV}$ (Figure $2 \mathrm{~S}$, supplementary material). It is important to observe that the bigger clusters correspond to the overlapping of small clusters of $50 \mathrm{~nm}$ in diameter approximately. It has been reported that the formation of these small Co clusters from ammoniacal solutions is due to that when the $\mathrm{NH}_{4}^{+}$ions are absorbed on the electrode surface, they stop the diffusion of the Co ad-atoms towards the growing cluster, which in turn, will induce the growth of smaller clusters. ${ }^{15}$

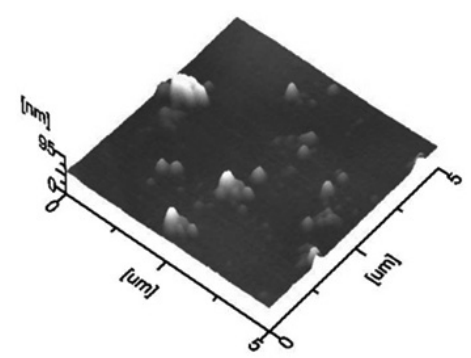

Figure 6. AFM image of the deposits obtained at $-820 \mathrm{mV}$ onto HOPG from

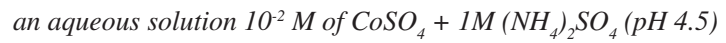

\section{CONCLUSIONS}

We have studied Co electrodeposition onto HOPG from $10^{-2}$ $\mathrm{M} \mathrm{CoSO}_{4}, 1 \mathrm{M}\left(\mathrm{NH}_{4}\right)_{2} \mathrm{SO}_{4}$ aqueous solution by using the voltammetric and potentiostatic techniques. Nucleation parameters such as nucleation rate, density of active nucleation sites and saturation nucleus were potential dependent. The $\Delta G$ energy calculated for the formation of stable nucleus was $8.21 \times 10^{-21} \mathrm{~J} /$ nuclei. The AFM images showed the formation of small Co clusters of 50-400 nm in diameter approximately.

\section{GLOSSARY OF SYMBOLS}

$k_{\mathrm{PR}}=$ Constant of the proton reduction reaction

$\Delta G=$ Energy required for the formation of a stable nucleus

$E_{\mathrm{c}}=$ Potential value in where the Co electrodeposition starts

$E_{\mathrm{e}}=$ Potential value in where the equilibrium $\mathrm{Co}^{2+}+2 \mathrm{e} \rightarrow \mathrm{Co}^{0}$ is expected

$N_{0}=$ Density number of active nucleation sites

$\mathrm{A}=$ Nucleation rate

$D=$ Diffusion Coefficient

$F=$ Faraday's constant

$\mathrm{c}=$ Cobalt concentration in solution

$\mathrm{M}=$ Molecular weight of cobalt

$\rho=$ Density of cobalt deposit

$z_{P R}=$ Charge of proton $=1$

$\mathrm{z}=$ Charge of cobalt cation $=2$

$\mathrm{K}_{\mathrm{B}}=$ Boltzmann's constant

$\mathrm{T}=$ Temperature of the solution

$N_{s}=$ Saturation number of nuclei

$n_{c}=$ Critical size of the Co nucleus

$\omega_{n+c}=$ Frequency of attachment of single atoms to the critical nucleus

$\Gamma=$ Non-equilibrium Zeldovich factor

$\gamma=$ Interfacial tension of nucleus with its motherphase 
$\theta=$ Contact angle $\theta$ between the nucleus and the substrate

$\alpha_{C o=}$ Transfer coefficient for Co reduction

\section{SUPPLEMENTARY MATERIAL}

Available on http://quimicanova.sbq.org.br, pdf file, with free access.

\section{ACKNOWLEDGMENTS}

We gratefully acknowledge financial support from CONACyT project APOY-COMPL-2008 No. 91261 and to the Universidad Autónoma del Estado de Hidalgo. We are also grateful to the reviewers of the manuscript for valuable suggestions.

\section{REFERENCES}

1. Grujicic, D.; Pesic, B.; Electrochim. Acta 2004, 49, 4719.

2. Gomez, E.; Valles, E.; J. Appl. Electrochem. 2002, 32, 693.

3. Floate, S.; Hyde, M.; Compton, R.G.; J. Electroanal. Chem. 2002, 523, 49.

4. Soto, A. B.; Arce, E. M.; Palomar-Pardave, M.; González, I.; Electrochim. Acta 1996, 41, 2647.

5. Myung, N.; Ryu, K. H.; Sumodjo, P. T. A.; Nobe, K.; Electrochemical Society Proceedings 1998, PV97, 270

6. Palomar-Pardave, M.; González, I.; Soto, A. B.; Arce, E. M.; J. Electroanal. Chem. 1998, 443, 125.

7. Mendoza-Huizar, L. H.; Rios-Reyes, C. H.; Rivera, M.; Galán-Vidal C. A.; Advances in Technology of Materials and Materials Processing 2006, 8,152

8. Correia, A. N.; De Oliveira, R. C. B.; Lima-Neto, P.; J. Braz. Chem. Soc. 2006, 17, 90 .

9. Gu, M.; Yang, F. Z.; Huang, L.; Yao, S. B.; Zhou, S. M.; Chin. Chem. Lett. 2004, 15, 981.

10. Mishra, K. G.; Singh, P.; Muir, D.; J. Appl. Electrochem. 2002, 32, 1391.

11. Fletcher, S.; Halliday, C. S.; Gates, D.; Westcott, L. T.; Nelson, G.; J. Electroanal. Chem. 1983, 159, 267.

12. Rios-Reyes, C. H.; Mendoza-Huizar, L. H.; Rivera, M.; J. Solid State Electrochem. 2010, 14, 659, DOI 10.1007/s10008-009-0816-3.

13. Gomez, E.; Marin, M.; Sanz, F.; Valles, E.; J. Electroanal. Chem. 1997, $422,139$.
14. Rios-Reyes, C. H.; Rivera, M.; Mendoza-Huizar, L. H. In Theoretical and Experimental Advances in Electrodeposition; Mendoza-Huizar, L. H., ed.; Research SignPost Publishers: Kerala, 2008, chap. 3.

15. Rivera, M.; Rios-Reyes, C. H.; Mendoza-Huizar, L. H.; Appl. Surf. Sci. 2008, 255, 1754.

16. Rios-Reyes, C. H.; Ramos-Lora, N.; Mendoza-Huizar, L. H.; RomeroRomo, M.; Granados-Neri, M.; Galán-Vidal, C. A. In Electrochemistry and Materials Engineering; Palomar-Pardavé, M.; Romero-Romo, M., eds.; Research SignPost Publishers: Kerala, 2007, chap. 3.

17. Rios-Reyes, C. H.; Granados-Neri, M.; Mendoza-Huizar, L. H.; Quim. Nova 2009, 32, 2382.

18. Abd El Rehim, S. S.; Abd El Wahaab, S. M.; Ibrahim, M. A. M.; Dankeria, M. A.; J. Chem. Technol. Biotechnol. 1998, 73, 369.

19. Tutunaru, B.; Patru, A.; Preda, M.; Rev. Chim. 2006, 57, 598.

20. Mendoza-Huizar, L. H.; Robles, J.; Palomar-Pardavé, M.; J. Electroanal. Chem. 2002, 521, 95.

21. Mendoza-Huizar, L. H.; Robles, J.; Palomar-Pardavé, M.; J. Electroanal. Chem. 2003, 545, 39.

22. Kabulska, F.; J. Appl. Electrochem. 2006, 36, 131.

23. Cui, C. Q.; Jiang, S. P.; Tseung, A. C. C.; J. Electrochem. Soc. 1990, 137, 3418

24. Bhuiyan, M. S.; Taylor, B. J.; Paranthaman, M.; Thompson, J. R.; Sinclair, J. W.; J. Mater. Sci. 2008, 43, 1644.

25. Bento, F. R.; Mascaro, L. H.; J. Braz. Chem. Soc. 2002, 13, 502.

26. Bard, A. J.; Faulkner, L. R.; Electrochemical methods. Fundamental and applications, Wiley: New York, 2001.

27. Scharifker, B. R.; Hills, G.; Electrochim. Acta 1983, 28, 879.

28. Scharifker, B. R.; Mostany, J.; J. Electroanal. Chem. 1984, 177, 13.

29. Heerman, L.; Tarallo, A.; Electrochem. Commun. 2000, 2, 85.

30. Palomar-Pardavé, M.; Scharifker, B. R.; Arce, E. M.; Romero-Romo, M.; Electrochim. Acta 2005, 50, 4736.

31. Mostany, J.; Mozota, J.; Scharifker, B. R.; J. Electroanal. Chem. 1984, $177,25$.

32. Serruya, A.; Mostany, J.; Scharifker, B. R.; J. Electroanal. Chem. 1999, $464,39$.

33. Milchev, A.; Electrocrystallization: Fundamentals of nucleation and growth, Kluwer Academic Publishers: Dordrecht, 2002.

34. Petrović, Ž.; Metikoš-Huković, M.; Grubač, Z.; Omanović S.; Thin Solid Films 2006, 513, 193.

35. Scharifker, B.; Rugeles, R.; Mozota, J.; Electrochim. Acta 1984, 29, 261.

36. Milchev, A.; J. Contemp. Phys. 1991, 32, 321. 


\section{COBALT ELECTRODEPOSITION ONTO HIGHLY ORIENTED PYROLYTIC GRAPHITE (HOPG) ELECTRODE} FROM AMMONIUM SULFATE SOLUTIONS

Luis Humberto Mendoza-Huizar* y Clara Hilda Rios-Reyes

Centro de Investigaciones Químicas, Mineral de la Reforma, Universidad Autónoma del Estado de Hidalgo, CP 42186, Hidalgo, México Margarita Rivera

Departamento Materia Condensada, Instituto de Física, Universidad Nacional Autónoma de México, Ciudad Universitaria, CP 04510, México D.F., México
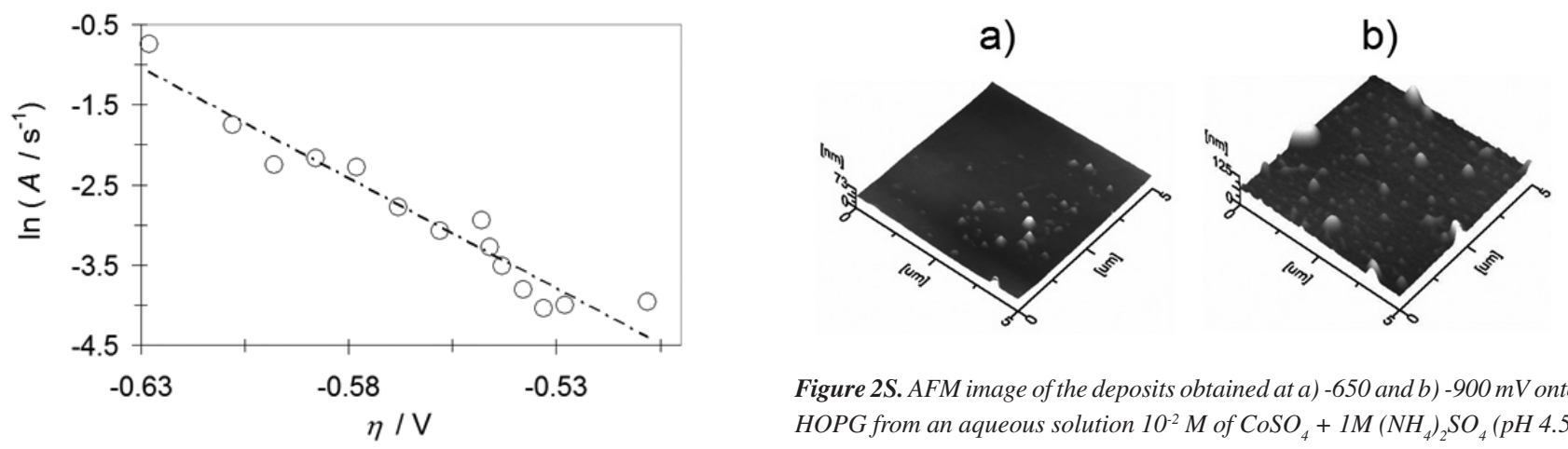

Figure 2S. AFM image of the deposits obtained at a) - 650 and b) - $900 \mathrm{mV}$ onto

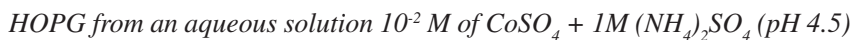

Figure 1S. In A vs $\eta$ plot, used to calculate the critical cluster's size according to Equation 13. The broken straight line corresponds to the linear fit of the experimental data 